\title{
Erratum to: Scaphoid Fractures and Nonunions
}

Alessio Pedrazzini FM/List of contributors: J J. Yao (ed.), Scaphoid Fractures and Nonunions, DOI 10.1007/978-3-31918977-2, missed to include an author in both printed and electronic versions. The error has been corrected and is reflected in both print and electronic versions.

The authors and affiliation detail is given below:

Alessio Pedrazzini, MD Department of Orthopaedic Surgery and Traumatology, Oglio Po Hospital, Cremona, Italy 